\title{
Formaldehyde-Doxorubicin Dual Polymeric Drug Delivery System for Higher Efficacy and Limited Cardiotoxicity of Anthracyclines
}

5

\begin{abstract}
We report the synthesis of a dual delivery system composed of a chemically bound $\mathrm{pH}$ responsive formaldehyde polymer prodrug and $\mathrm{pH}$-responsive doxorubicin loaded nanoparticles to increase the therapeutic index of anthracyclines by limiting the cardiotoxicity of doxocrubicin by working in synergy with formaldehyde to enable the formation of DOX-DNA adducts. Polyacrylates bearing 1,2- and 1,3-pendant diols were synthesized via reversible addition fragmentation chain transfer (RAFT) polymerization to conjugate formaldehyde, forming 5- or 6-membered acetal rings with tunable conjugation percentages $(1.5-10 \mathrm{wt} \%)$ for controlled release in acidic environments of the tumor extracellular matrix. The formaldehyde-conjugated prodrugs are then combined with polyester nanoparticles formed by intermolecular crosslinking via oxime click chemistry of less than $200 \mathrm{~nm}$ in size containing $14 \mathrm{wt} \%$ encapsulated Doxorubicin (DOX). Release kinetics show a sustained release of both DOX and formaldehyde at $\mathrm{pH} 5.0$, mimicking the low $\mathrm{pH}$ of the tumor environment whereas insignificant release was recorded at physiological $\mathrm{pH}$. The cell viability of the dual delivery system combination was evaluated in $4 \mathrm{~T} 1$ breast cancer cells resulting in a considerably increase of cell death of about 4-fold compared to free DOX alone. The resulting polymeric delivery system is the first example reported of a DOX and formaldehyde co-administration, demonstrating the potential significant effect of formaldehyde for an improved anti-cancer efficacy of DOX and towards a reduced cardiotoxicity of DOX
\end{abstract}

Keywords: DOX, formaldehyde, nanosponge, cardiotoxicity 2010 MSC: 00-01,99-00

Preprint submitted to Journal of Information Processing and Management 


\section{Introduction}

The implementation of synergistic drug therapies into the clinic is widely accepted due to enhanced efficacy [1], reduced dosage requirements, and decreased toxicity [2] of the individual drug components. Specifically Doxorubicin (DOX), a broad spectrum anti-tumor antibiotic is known to develop chemo resistance [3] like many other anthracycline-based therapeutics and moreover its clinical use is limited by acute and chronic cardiotoxicity.[4-6] The DOX-induced cardiotoxicity is attributed to the generation of reactive oxygen species (ROS) and the formation of the toxic metabolite doxorubicinol [7-8] as result of some of the main molecular events that damage cardiomyocytes, cardiac muscle cells, and can lead to heart failure many years after treatment.[9]Therefore, it is prevalent to seek non-overlapping mechanisms of action in drug combinations with doxorubicin to avoid resistance, increasing the sensitivity of the therapeutic and improving the therapeutic index by protection of the cardiac system.

It has been reported that a family of acyloxyalkyl prodrugs release butyric acid and formaldehyde upon metabolic hydrolysis and can act in synergy with doxorubicin to increase substantially the formation of DOX-DNA adducts, DOX's primarily intercalation complex as its active anti-cancer mechanism.[6, 10-14] DOX-DNA adducts do not only enhance the therapeutics efficacy by 3-4 fold [15] but also reduce cardiotoxicity. [10] It is postulated that formaldehyde reacts with doxorubicin to form a DOX $-\mathrm{N}=\mathrm{CH}_{2}$ Schiff's base which is readily reacting with the amino groups on the guanine in GpC DNA sequences. [16-17] Doxorubicin is thereby sequestered, preventing DOX cycling and enzymatic degradation to generate ROS and the toxic metabolite, while attenuating at the same time cancer cell growth by forming the desired DOX-DNA adduct. [10] It is to note that metabolized free formaldehyde has not shown 60 any adverse toxicity. [10] This finding and others has inspired the synthesis of doxorubicin-formaldehyde conjugates and several prodrugs such as Doxoform (DoxF), and Doxsaliform (DoxSF) have been produced and tested. [15-18] In addition to the aforementioned benefits of this drug combination, a higher uptake into multi-drug resistant MCF-7/Adr cells was also reported. [16] While these are promising results, 
the acyloxyalkyl ester prodrugs and Dox-formaldehyde prodrugs release formaldehyde by hydrolysis and metabolize very quickly with the stability and shelf-life of an aqueous therapeutic solution being limited to a few minutes. [15]

We sought to design a dual $\mathrm{pH}$-responsive delivery system for formaldehyde and doxorubicin that exemplifies a release mechanism for formaldehyde and DOX using $\mathrm{pH}$-responsive materials to trigger the release in the tumor extracellular matrix that is known having a lower acidity than other tissues. [19-21] Polymer prodrugs seemed ideal as they can bind a multitude of small molecules and the binding of gaseous compounds is known for other attempts to enable a controlled release from a stable carrier. For example, carbon monoxide. [22-23] and nitric oxide [24-26] have been studied to increase the potency of other chemotherapeutics or to reverse multidrug resistance.

Thus, to design a formaldehyde-DOX dual drug delivery system, we opted to use a polymeric prodrug-nanoparticle combination, in which the formaldehyde is bound to an acrylate based hydrophilic polymer and the formaldehyde can be conjugated in varied percentages. As ideal monomers, we choose solketal acrylate (1,2-diol) and 2(acryloyloxy)ethyl2,2,5-trimethyl-1,3-dioxane-5-carboxylate diol (1,3-diol) which upon reaction with formaldehyde forms the corresponding acetal derivative resulting in 5 - and 6-membered rings. Here, we wanted to explore if the ring size has an effect on the kinetics of the ring cleavage to release formaldehyde. For Doxorubicin, we selected a sustained nanoparticle delivery system that could be combined with the polymeric prodrug. In our previous work, we reported on a nanoparticle which is crosslinked by forming ketoxime linkages, derived from a reaction of 2-oxepane-1,5-dione (OPD)containing polyesters in the backbone of the polymer [27]. Upon full reduction of the ketoximes, the nanoparticles will contain alkoxyamine units and differences in release kinetics of hydrophobic drugs were observed. For this work, we aimed to investigate partially reduced particles, containing 50\% ketoxime and 50\% alkoxyamine crosslinks. We thought that doxorubicin, with a slightly higher water solubility would benefit from a release system designed for a faster release, close to the expected rapid release of formaldehyde from the prodrug.

In this report, we present the synthesis of the first $\mathrm{pH}$ - responsive dual delivery system with a concerted delivery of both formaldehyde and doxorubicin. Two 
formaldehyde-polymer prodrugs forming acetal functionalities were prepared by reversible addition fragmentation chain transfer (RAFT) polymerization with the gaseous compound to test for tailoring release profiles. Secondly, a crosslinked polyester nanoparticle was designed and synthesized for the delivery of doxorubicin with fast release kinetics (Figure 1). Release kinetics by a Purpald ${ }^{\circledR}$ colorimetric assay identified the five-membered acetal ring be slightly favorable for release at $\mathrm{pH} 5.0$ over physiological $\mathrm{pH}$ and cell toxicity studies with mammalian breast cancer $4 \mathrm{~T} 1$ cells were conducted. The effect of sustained and synergistic delivery is indicative of the cardiotoxicity of DOX.

\section{Materials and Methods}

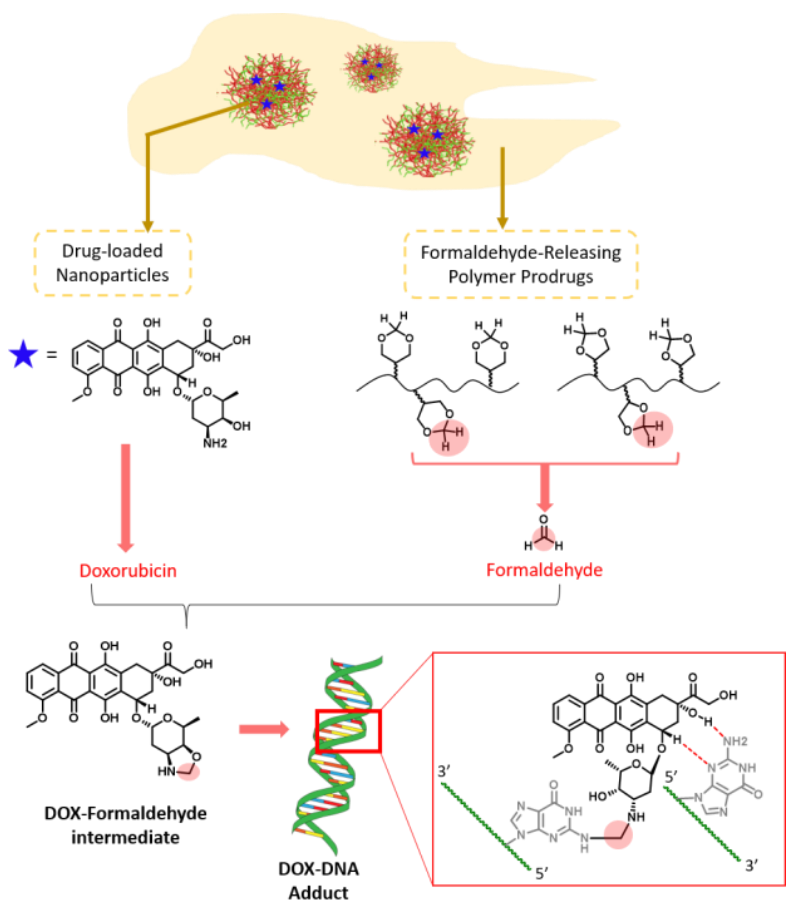

Fig. 1. Resulting polymeric matrix composed of formaldehydereleasing polyacrylate prodrugs and DOX-loaded of partially reduced ketoxime/alkoxyamine polyester nanoparticles that forms the DOXFormaldehyde intermediate and results in DOX-DNA adducts. 
2.1. Materials. All reagents were purchased from Millipore Sigma, Tokyo Chemical Industry America, or Fisher Scientific and used without further purification unless otherwise specified. Methoxy PEG acrylate was passed through a column of inhibitor remover prior to polymerization. Spectra/Por ${ }^{\circledR}$ dialysis tubing $(\mathrm{MWCO}=1000 \mathrm{Da})$ and Float-a-Lyzer ${ }^{\circledR}(\mathrm{MWCO}=0.1-0.5 \mathrm{kDa})$ were purchased from Spectrum Laboratories Inc. 2-(n-butyltrithiocarbonate)-propionic acid was prepared according to literature. ${ }^{28}$ ${ }^{1} \mathrm{H}$ and ${ }^{13} \mathrm{C}$ NMR spectra were recorded on JEOL ECX-400 and JEOL ECA-600 II spectrometers. Chemical shifts were referenced to solvent resonance signals. Gel permeation chromatography (GPC) was conducted on a ToSOH EcoSEC HLC8320GPC system equipped with a refractive index detector, UV-8320 detector, and TSKgel HHR columns (7.8x300mm G5000HHR, G4000HHR, and G3000HHR) with $\mathrm{N}$-dimethylformamide (DMF) as the eluent at a flow rate of $1 \mathrm{~mL} / \mathrm{min}$. High performance liquid chromatography (HPLC) analysis of drug concentration was conducted using a Thermo Fisher Ultimate 3000 HPLC system and Phenomenex column (Luna $5 \mu \mathrm{C} 8(2) 100 \AA, 150 \times 4.6 \mathrm{~mm}, 5 \mu \mathrm{m}$ ) with a gradient solvent system of $100 \%$ A to $30 \%$ A:70\% B over 12 min. Solvent A was water with 1\% trifluoracetic acid (TFA), and solvent B was $90 \%$ acetonitrile $/ 10 \%$ water with $1 \%$ TFA. The column was maintained at $35^{\circ} \mathrm{C}$ and the absorbance was measured at $475 \mathrm{~nm}$. Transmission electron microscopy (TEM) was perform using JEOL JEM-210F microscope operated at 200 $\mathrm{kV}$. Samples for the transmission electron microscope (TEM) were prepared by dissolving nanoparticles $(\sim 2.0 \mathrm{mg})$ in $0.22 \mu \mathrm{m}$ filtered acetonitrile $(\mathrm{ACN})$ and stained with 3 drops of 3\% phosphotungstic acid monohydrate. Ultrathin Carbon Type-A 400 Mesh Copper Grids were prepared by dipping into the sample solution three times and allowing to dry at room temperature overnight. Dynamic Light Scattering (DLS) was measured on a Malvern Zetasizer Nano system with a fixed angle of $173^{\circ}$ at $25^{\circ} \mathrm{C}$ using the Molecular Weight function. The sample solutions were made in a $0.1 \mathrm{mg} / \mathrm{mL}$ concentration in $0.22 \mu \mathrm{m}$ filtered tetrahydrofuran (THF). Colorimetry assays were measured using a microplate absorbance reader Perkin Elmer HTS 7000 Bio Assay Reader at $495 \mathrm{~nm}$.

\subsection{Methods}


2.2.1. Prodrugs Synthesis and Characterization. To a sealed 1-dram vial, solketal acrylate (1,2-DA, $100 \mathrm{mg}, 0.595 \mathrm{mmol})$ or 2-(acryloyloxy)ethyl2,2,5-trimethyl-1,3dioxane-5-carboxylate (1,3-DA, $1.33 \mathrm{~g}, 2.7 \mathrm{mmol})$, methoxy PEG acrylate (1.03 g, 2 $\mathrm{mmol}$ ), and 2-(n-butyltrithiocarbonate)-propionic acid (BTPA, $27.6 \mathrm{mg}, 0.116 \mathrm{mmol}$ ), with azobisisobutyronitrile (AIBN, $1.9 \mathrm{mg}, 12 \mu \mathrm{mol}$ ) were dissolved in degassed DMSO in a 1:1 monomer:DMSO ratio, and the mixture was degassed for $20 \mathrm{~min}$. The reaction was heated at $65^{\circ} \mathrm{C}$ for $7 \mathrm{~h}$ then transferred to dialysis tubing ( $\mathrm{MWCO}=1000$ Da) and dialyzed against 1:1 mixture DCM:MeOH for 24 h. $(1.12$ g, 98\%, Mn $=12$ $\mathrm{kDa}, \mathrm{Mw}=13.9 \mathrm{kDa}, \mathrm{Ð}=1.15, \mathrm{MPEGA}=80 \%, 1,2-\mathrm{DA}=20 \%){ }^{1} \mathrm{H} \mathrm{NMR}(600 \mathrm{MHz}$, $\left.\mathrm{CDCl}_{3}\right) \delta(\mathrm{ppm}): 0.93\left(3 \mathrm{H}, \mathrm{t},-\mathrm{S}\left(\mathrm{CH}_{2}\right)_{3} \mathrm{CH}_{3}\right), 1.39\left(6 \mathrm{H}, \mathrm{d}, \mathrm{CH}_{3}\right), 1.63(\mathrm{~s}, \mathrm{CH}), 1.90(\mathrm{~s}$, $\mathrm{CH}), 2.29(\mathrm{~s}, \mathrm{CH}), 3.37\left(\mathrm{~s},-\mathrm{OCH}_{3}\right), 3.55\left(\mathrm{t},-\mathrm{O}=\mathrm{COCH}_{2}-\right), 3.64\left(\mathrm{~s},-\mathrm{OCH}_{2} \mathrm{CH}_{2} \mathrm{O}-\right), 4.15$ $\left(\mathrm{s},-\mathrm{O}=\mathrm{COCH}_{2}-\right), 4.23\left(\mathrm{~s},-\mathrm{O}=\mathrm{COCH}_{2}-\right), 4.31\left(\mathrm{~s},-\mathrm{O}=\mathrm{COCH}_{2}-\right) .(243 \mathrm{mg}, 67 \%, \mathrm{Mn}=$ $11.0 \mathrm{kDa}, \mathrm{Mw}=12.8 \mathrm{kDa}, \mathrm{Ð}=1.17, \mathrm{MPEGA}=67 \%, 1,3-\mathrm{DA}=33 \%){ }^{1} \mathrm{H}$ NMR $(600$ $\left.\mathrm{MHz}, \mathrm{CDCl}_{3}\right) \delta$ (ppm): $0.93\left(3 \mathrm{H}, \mathrm{t},-\mathrm{S}\left(\mathrm{CH}_{2}\right)_{3} \mathrm{CH}_{3}\right), 1.19\left(3 \mathrm{H}, \mathrm{s}, \mathrm{CH}_{3}\right), 1.39\left(6 \mathrm{H}, \mathrm{d}, \mathrm{CH}_{3}\right)$, $1.63(\mathrm{~s}, \mathrm{CH}), 1.90(\mathrm{~s}, \mathrm{CH}), 2.29(\mathrm{~s}, \mathrm{CH}), 3.37\left(\mathrm{~s},-\mathrm{OCH}_{3}\right), 3.55\left(\mathrm{t},-\mathrm{O}=\mathrm{COCH}_{2}-\right), 3.64$ (s, $\left.-\mathrm{OCH}_{2} \mathrm{CH}_{2} \mathrm{O}-\right), 4.15$ (s, - $\left.\mathrm{O}=\mathrm{COCH}_{2}-\right), 4.23$ (s, - $\left.\mathrm{O}=\mathrm{COCH}_{2}-\right), 4.31$ (s, - $\left.\mathrm{O}=\mathrm{COCH}_{2}-\right)$ (Figures S1, S4- S5).

2.2.2. Polymer Deprotection. To a 1 -dram vial with a stir bar, $\mathrm{P}(\mathrm{MPEGA}-\mathrm{co}-1,2-$ DA) (600 mg, $0.388 \mathrm{mmol}$ acetonide) was dissolved in DI water (1.5 mL). Trifluoroacetic acid $(11.88 \mu \mathrm{L}, 0.115 \mathrm{mmol})$ was added and the reaction stirred for 18 h. The solution was transferred to dialysis tubing $(\mathrm{MWCO}=1000 \mathrm{Da})$ and dialyzed against $\mathrm{MeOH}$ for $8 \mathrm{~h}$. The polymer was concentrated and dried in vacuo. (480 mg, $80 \%$ ). Deprotection was confirmed by ${ }^{1} \mathrm{H}$ NMR. Procedure conditions are the same for P(MPEGA-co-1,3-DA).

2.2.3. Formaldehyde Attachment to form Prodrugs. Deprotected P(MPEGA-co1,2-DA) (200 mg, 1 equiv.) was weighed into a 1 -dram vial with stir bar. Formaldehyde solution (37 wt \% in water, $241 \mu \mathrm{L}, 6 \mathrm{mmol}, 50$ equiv./diol) was added to the reaction vial, and the mixture was stirred at room temperature for $2 \mathrm{~h}$. Methanol was removed under rotary evaporation and then resuspended in cell culture grade water and filtered using ultra centrifugal filters $(\mathrm{MWCO}=3 \mathrm{kDa})$. Samples were centrifuged at $14 \mathrm{~K} \mathrm{rpm}$ for 40 minutes to remove formaldehyde oligomers and the filtrate discarded. The collected material in cell culture grade water was lyophilized. The product was 
collected and stored at $4{ }^{\circ} \mathrm{C}$ until used. Attachment was confirmed by ${ }^{1} \mathrm{H}$ NMR and HSQC (Figure S6). Procedure conditions are the same for deprotected P(MPEGA-co1,3-DA).

2.2.4. In Vitro Release of Formaldehyde from Prodrugs. Release of formaldehyde from the prodrugs was determined using Float-A-Lyzer ${ }^{\circledR}$ dialysis tubing (MWCO: $0.1 \mathrm{~K}-0.5 \mathrm{~K})$. A sample of prodrug $(10.0 \mathrm{mg})$ was suspended in $1.0 \mathrm{~mL}$ of either acidic buffer (NaOAc-acetic acid, $\mathrm{pH}$ 5.0) or PBS (pH 7.4) and transferred to a Float-ALyzer ${ }^{\circledR}$ dialysis pod. The pod was then placed in a $50-\mathrm{mL}$ Falcon tube containing 18.0 $\mathrm{mL}$ of the corresponding buffer solution. Falcon tubes were placed in an oil bath at $37^{\circ} \mathrm{C}$ and media was stirred constantly using a magnetic stir bar. Samples of $100 \mu \mathrm{L}$ were withdrawn from the sink at $0.5,1,1.5,2,4,6,24,48,72 \mathrm{~h}$ and every two days following. An equal amount of fresh media was added to the sink after each withdrawal to maintain sink conditions. The amount of formaldehyde released at each time point was quantified using a colorimetric assay. A $50 \mu \mathrm{L}$ aliquot of sample was placed in the well of a 96well plate and $50 \mu \mathrm{L}$ of $2 \mathrm{mM} \mathrm{NaIO} 4$ in $0.2 \mathrm{M} \mathrm{NaOH}$ was added to the sample. The plate was then incubated for 20 minutes at room temperature in the dark. After 20 minutes, $100 \mu \mathrm{L}$ of a $34 \mathrm{mM}$ solution of 4-amino-3-hydrazino-5-mercapto-1,2,4-triazole (Purpald $($ ) in $2 \mathrm{M} \mathrm{NaOH}$ was added to the sample and incubated at room temperature for 20 minutes. Finally, $100 \mu \mathrm{L}$ of a $33 \mathrm{mM} \mathrm{NaIO} 4$ in $0.2 \mathrm{M} \mathrm{NaOH}$ was added to each well for color development. The absorbance was measured at $550 \mathrm{~nm}$ immediately and formaldehyde concentration in each sample was determined against a standard curve.

\subsubsection{Synthesis of Partially Reduced Ketoxime/Alkoxyamine Nanoparticles.} $\mathrm{P}(\mathrm{VL}-\mathrm{co}-\mathrm{OPD})$ (8\% OPD, $150 \mathrm{mg}$, $3722.12 \mathrm{~g}$ mol-1, $\left.3.67 \times 10^{-4} \mathrm{~mol}\right)$ was dissolved in dichloromethane $(134.2 \mathrm{~mL})$ then added to a $200 \mathrm{~mL}$ round bottom flask. O,O'(((oxybis(ethane-2,1-diyl))bis(oxy))bis(ethane-2,1-diyl))bis(hydroxylamine) (82.4 mg, $1.71 \times 10^{-5} \mathrm{~mol}, 1$ equiv.) was dissolved in dichloromethane $(2.0 \mathrm{~mL})$ and added quickly to the polymer solution at a fast vortex. After $2 \mathrm{~h}$, sodium cyanoborohydride $(11.56 \mathrm{mg}$, $3.67 \times 10-4$ mol, 0.5 equiv.) and a catalytic amount of saturated sodium bicarbonate solution $(300 \mu \mathrm{L})$ were added directly to the reaction flask. The reaction stirred for $2 \mathrm{~h}$ then was transferred to Thermo Scientific ${ }^{\mathrm{TM}}$ SnakeSkin $^{\mathrm{TM}}$ 10K MWCO Dialysis Tubing. The solution was dialyzed against a 1:1 mixture of $\mathrm{MeOH} / \mathrm{DCM}$ for $48 \mathrm{~h}$, with 
3-4 solvent changes per day. The solution was filtered with a $0.45 \mu \mathrm{m}$ filter to remove solid salt particulates and solvent was removed via rotary evaporation. The product was dried in vacuo to yield a light tan waxy solid ( $80 \%$ yield). ${ }^{1} \mathrm{H}$ NMR (400 $\left.\mathrm{MHz}, \mathrm{CDCl}_{3}\right)$ : $\delta$ (ppm): 0.90 (d, 6H); 1.6-1.75 (m); 2.23-2.43 (m); 2.25-2.7 (m); 2.7-2.84 (m); $3.4(\mathrm{t})$; $3.65(\mathrm{~m}) ; 4.0(\mathrm{t}) ; 4.3-4.4(\mathrm{~m}) .{ }^{13} \mathrm{C} \mathrm{NMR}\left(600 \mathrm{MHz}, \mathrm{CDCl}_{3}\right): \delta$ 21.32, 25.53, 28.00, $33.62,63.85,67.88,173.26$ (Figure S8 and S9).

DOX Encapsulation. DOX $(15.0 \mathrm{mg})$ was solubilized in dimethyl sulfoxide (DMSO) $(45 \mu \mathrm{L})$ in a $1.5 \mathrm{~mL}$ centrifuge tube. Nanoparticles $(60.0 \mathrm{mg}, 8 \%$ OPD, $2.7 \mathrm{mM}, \sim 140$ $\mathrm{nm}$ ) were added to the DOX centrifuge tube and an additional $155 \mu \mathrm{L}$ DMSO were added to solubilize the mixture. The mixture was divided equally into $61.5 \mathrm{~mL}$ centrifuge tubes, approximately $25 \mu \mathrm{L}$ each. Cell culture grade water containing $1 \% \mathrm{D}$ $\alpha$-tocopherol polyethylene glycol 1000 succinate $(1 \mathrm{~mL})$ was added to each centrifuge tube and vortexed to induce DOX encapsulation. D- $\alpha$-tocopherol polyethylene glycol 1000 succinate is added to coat the particles during encapsulation and aid in resuspension in aqueous media during drug release studies. The mixture was then centrifuged at 14000 RPM for $40 \mathrm{~min}$. The supernatant was decanted, fresh cell culture grade water $(1 \mathrm{~mL})$ was added to the particle pellet and vortexed until particles were resuspended. Centrifugation was repeated at 14000 RPM for $40 \mathrm{~min}$, then the supernatant was decanted to remove any nonincorporated drug. Cell culture grade water $(0.5 \mathrm{~mL})$ was added to the mixture, frozen, and lyophilized to produce DOX-loaded nanoparticles (DOX-NP). HPLC analysis confirmed encapsulation of DOX at an average of $14 \mathrm{wt} \%$ with $68 \%$ efficiency.

2.2.6. In Vitro Release of DOX. DOX-loaded nanoparticles were suspended in 1 $\mathrm{mL}$ of either sodium acetate-acetic acid buffer $(\mathrm{pH} 5$ ) or PBS (pH 7.4) containing $0.1 \%$ v/v Tween-80 as a surfactant. The suspended DOX-NP were transferred to Float-aLyzer® dialysis pod (MWCO: $1000 \mathrm{kD}$ ). The pods were placed into 50-mL Falcon tube containing $18 \mathrm{~mL}$ of the corresponding release media. Falcon tubes were placed in an oil bath at $37^{\circ} \mathrm{C}$ and media was stirred constantly using a magnetic stir bar. Samples of $150 \mu \mathrm{L}$ were collected from the sink after 1, 2, 4, 6, 24, 48 and 72 hours. An equal amount of fresh media was added to the sink after each sample withdrawal to maintain sink conditions. The amount of DOX released was quantified using HPLC at $475 \mathrm{~nm}$ 
and $35^{\circ} \mathrm{C}$ with a gradient solvent system of $100 \%$ A to $30 \%$ A:70\% B over $12 \mathrm{~min}$.

Solvent A was water with $1 \%$ trifluoracetic acid (TFA), and solvent B was $90 \%$ acetonitrile/10\% water with $1 \%$ TFA.)

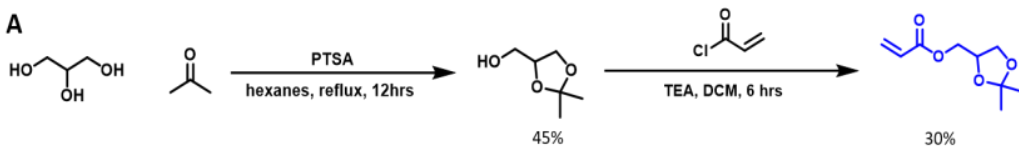

2. TEA, 5 min $54 \%$

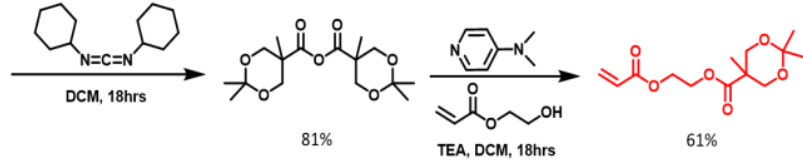
TEA, DCM, 18hrs

61

C

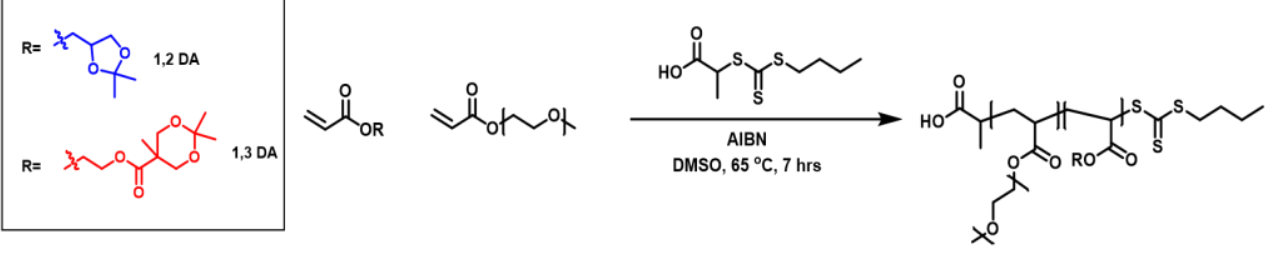

Fig. 2. (A) Synthesis of monomer solketal acrylate (1,2DA), (B) synthesis of monomer 2-(acryloyloxy)ethyl2,2,5-trimethyl-1,3dioxane-5-carboxylate (1,3DA), and (C) RAFT polymerization to form polyacrylates with protected diols.

CHO-P(MPEGA-co-1,2DA)-Acetal or CHO-P(MPEGA-co-1,3DA)-Acetal with the

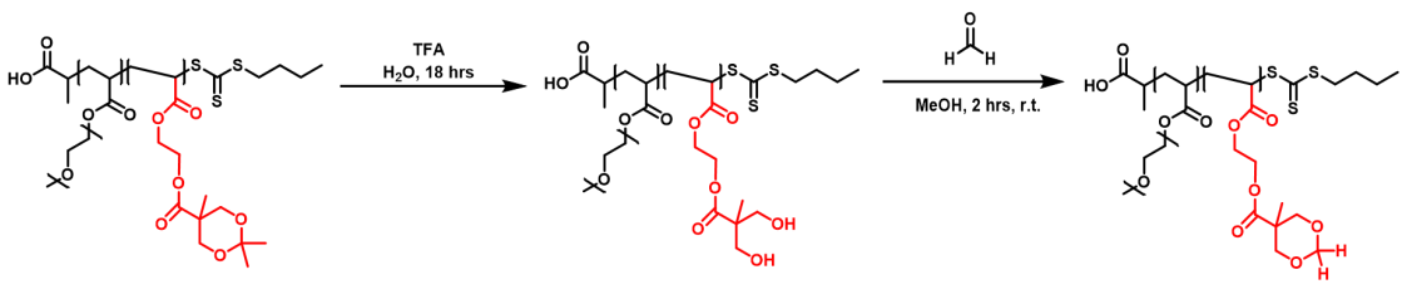

Fig. 3. Deprotection step of polyacrylate P(MPEGA-co-1,3DA) and formaldehyde attachment to yield the resulting prodrug CHOP(MPEGA-co-1,3DA). Same conditions were used for P(MPEGA-co-1,2DA).

DOX-NP were conducted in mouse breast cancer cells (4T1 cells). 4T1 cells were seeded into a 96-well plate with either DOX, free formaldehyde, CHO-P(MPEGA-co1,2DA) or CHO-P(MPEGA-co-1,3DA) polyacrylate-based prodrugs, DOX with formaldehyde (formalin solution), or DOX with the polyacrylate-based prodrug at 0.01 , $0.1,1$ and $10 \mu \mathrm{g} / \mathrm{mL}$ were incubated for 24 hours. A colorimetry cell viability assay, CellTiter 96® Aqueous Non-Radioactive Cell Proliferation Assay (MTS), was used to 
test cytotoxicity against a control (cells without treatment). Cell viability was measured at $495 \mathrm{~nm}$ with clear phosphate buffered saline (PBS) as blank samples in Perkin-Elmer HTSoft 3000 plate reader instrument.

\section{Results and Discussion}

To successfully deliver formaldehyde we had to find ways to immobilize the gaseous compound and chemically bind it to a polymeric backbone so that premature hydrolysis and release is prevented. Therefore, we thought to form acetal units by reacting diols with the carbonyl functionality of formaldehyde. Acetal formation and cleavage is reversible, and the ring size of the acetal unit can play a role in the deprotection of the diols at lower $\mathrm{pH}$. In light of this, we decided to synthesize two acetonide acrylate derivatives which can then be copolymerized successfully with a hydrophilic acrylate by RAFT polymerization. [29] Upon forming the protected polymers, the diols are deprotected and are available for post-functionalization with formaldehyde. The first protected monomer, solketal acrylate (1,2-DA), was synthesized by esterification reaction of acryloyl acrylate and solketal [30-31] (Figure 2A). The second protected monomer, 2-(acryloyloxy)ethyl2,2,5-trimethyl-1,3-dioxane-5-carboxylate (1,3-DA), was synthesized by esterification of 2,2,5-trimethyl-1,3-dioxane-5-carboxylic anhydride [32-33] with hydroxyethyl acrylate [30] (Figure 2B). Both monomers were obtained with considerable yield ( $30 \%$ and $60 \%$ respectively) and characterized using ${ }^{1} \mathrm{H}$ nuclear magnetic resonance (NMR). 
Table 1. Molecular weight and formaldehyde attachment data for both CHO-P(MPEGA-co-1,2DA) and CHO-P(MPEGA-co-1,3DA) at two ratios of MPEGA:DA 60:40 and 80:20

\begin{tabular}{|c|c|c|c|c|c|c|c|}
\hline Polymer & $\begin{array}{l}\text { Monomer } \\
\text { Feed Ratio } \\
\text { (MPEGA:DA) }\end{array}$ & $\begin{array}{c}\text { Polymer } \\
\text { Composition }^{\mathrm{a}} \\
\text { (MPEGA:DA) }\end{array}$ & $\begin{array}{r}\mathrm{M}_{\mathrm{n}^{\mathrm{a}}} \\
(\mathrm{g} / \mathrm{mol})\end{array}$ & $\begin{array}{r}\mathrm{M}_{\mathrm{n}}^{\mathrm{b}} \\
(\mathrm{g} / \mathrm{mol})\end{array}$ & $\begin{array}{r}\mathrm{M}_{\mathrm{w}}^{\mathrm{b}} \\
(\mathrm{g} / \mathrm{mol})\end{array}$ & $\begin{array}{l}\mathrm{M}_{\mathrm{w}} / \mathrm{M}_{\mathrm{n}}^{\mathrm{b}} \\
(\mathrm{g} / \mathrm{mol})\end{array}$ & $\begin{array}{l}\text { Formaldehyde } \\
\text { (wt\%) }\end{array}$ \\
\hline CHO-P(MPEGA-co- & $60: 40$ & $56: 44$ & 13,400 & 10,900 & 12,000 & 1.11 & 9.81 \\
\hline $1,2 \mathrm{DA})$ & $80: 20$ & $80: 20$ & 12,400 & 10,600 & 11,400 & 1.08 & 3.92 \\
\hline CHO-P(MPEGA-Co- & $60: 40$ & $65: 35$ & 11,400 & 11,000 & 12,800 & 1.17 & 6.45 \\
\hline $1,3 \mathrm{DA})$ & $80: 20$ & $81: 19$ & 12,300 & 11,100 & 12,400 & 1.11 & 1.50 \\
\hline
\end{tabular}

${ }^{\text {a }}$ Polymer composition and $\mathrm{M}_{\mathrm{n}}$ determined by $600 \mathrm{MHz}{ }^{1} \mathrm{H}$ NMR in $\mathrm{CDCl}_{3} .{ }^{\mathrm{b}}$ Molecular weight and polydispersity measured by $\mathrm{GPC}$ at $60{ }^{\circ} \mathrm{C}$ in $\mathrm{DMF}$ with $\mathrm{LiBr}(1 \mathrm{~g} / \mathrm{L})$ using polystyrene calibration and a flow rate of $1 \mathrm{~mL} / \mathrm{min}$. $\mathrm{Mn}_{\text {theo }}$ is $10,000 \mathrm{~g} / \mathrm{mol}$.

Each monomer, 1,2-DA or 1,3-DA, was copolymerized together with poly(ethylene glycol) acrylate (MPEGA) to add hydrophilicity and viscosity to the final polymer via RAFT polymerization with 2-(n-butyltrithiocarbonate)-propionic acid (BTPA) selected as chain transfer reagent (Figure 2C). The resulting polymers were copolymers in varied ratios of 60:40 and 80:20 MPEGA:(1,2- or 1,3-DA) with a molecular weight of $10,000 \mathrm{~g} / \mathrm{mol}$ and reasonable dispersity of 1.10 (Table S3). For this work, we selected four polymers for our studies, two copolymers of MPEGA and 1,2-DA (P(MPEGA-co1,2DA)) and two copolymers of MPEGA and 1,3-DA (P(MPEGA-co-1,3DA)) with ratios of $60: 40$ and 80:20 (Table 1).

One might question, why we not sought to prepare formaldehyde protected monomers directly which would form the desired polymers in one step. Forming the

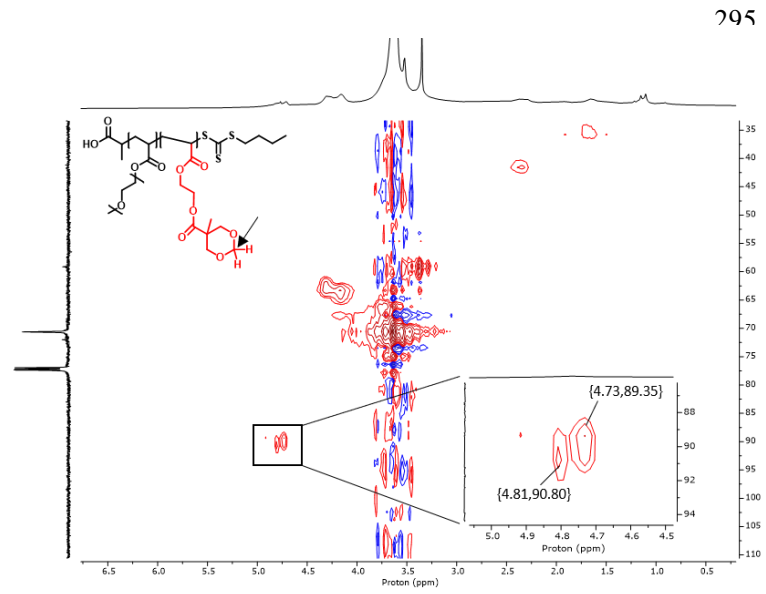

Fig. 4. Representative HSQC spectra of CHO-P(MPEGA-co-1,3DA) prodrug containing chemically bound formaldehyde. acetal from

glycerol with acetone instead of using formaldehyde, avoids obtaining a glycerol formal, which contain both a 5membered and a 6-membered acetal. However, 
if acetone reacts with glycerol only the 5-membered ring acetal will be favored (Figure 2A). Therefore, the synthesis procedure has two additional synthetic steps, a deprotection step and post-modification with formaldehyde, to study both polymers with 5-membered and 6-membered acetals incorporated (Figure 3). The deprotection was carried out by trifluoroacetic acid at room temperature. The resulting polymers were characterized by ${ }^{1} \mathrm{H}$ nuclear magnetic resonance (NMR) and gel permeation chromatography (GPC) having molecular weights $\sim 12 \mathrm{~K}$ and polydispersities $\left(\mathrm{M}_{\mathrm{w}} / \mathrm{M}_{\mathrm{n}}\right)$ of around 1.10 for all four polymers studied (Table 1).

315 Post-modification of the diols was achieved by mixing the deprotected copolymers with excess formaldehyde in methanol solution to form the prodrugs (Figure 3). An excess of 50 equivalents of formaldehyde was chosen since there is propensity to form solvent adducts and oligomers which would impede the formation of the acetal.

A

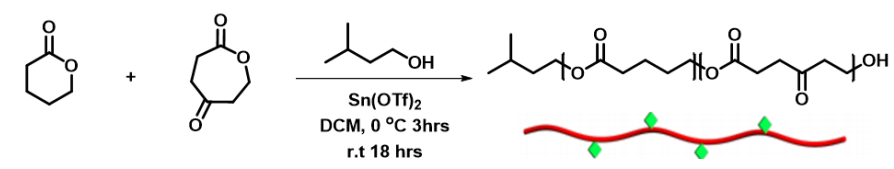

B

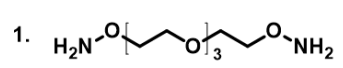
DCM, r.t, 2 hrs

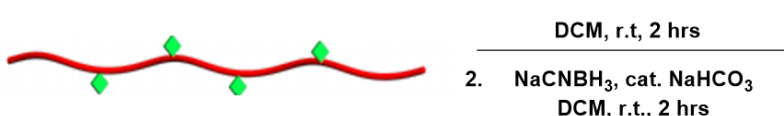
DCM, r.t., 2 hrs

Purification steps were conducted very carefully to remove any unattached

320 formaldehyde using a combination of rotary evaporation, high vacuum, centrifugal filtration and lyophilization. The final conjugated material was characterized via heteronuclear single quantum correlation (HSQC) spectroscopy. HSQC provides a correlation between chemical shifts in the ${ }^{1} \mathrm{H}$ and ${ }^{13} \mathrm{C}$ NMR identifying the protons to 


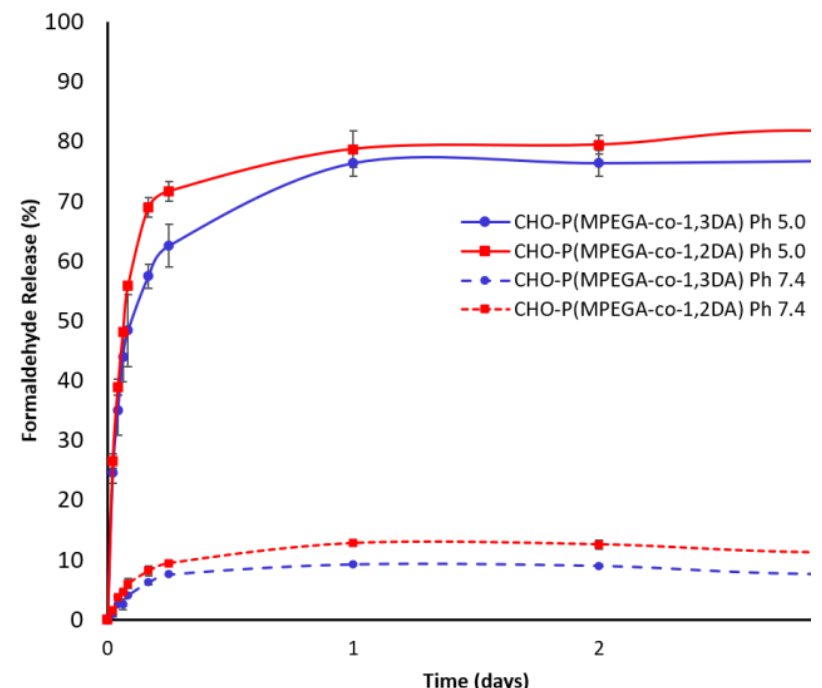

Fig. 5. Release of formaldehyde from $40 \% 1,2 \mathrm{DA}$ CHO-P(MPEGA-co1,2DA) (red lines) and 40\% 1,3DA CHO-P(MPEGA-co-1,3DA) (blue lines) prodrugs in sodium acetate-acetic acid buffer ( $\mathrm{pH} 5.0)$ and $\mathrm{PBS}(\mathrm{pH} 7.4)$ at $37{ }^{\circ} \mathrm{C}$ over 3 days. Reported values are averages of measurements in triplicate. the corresponding carbons to which they are attached. The collected spectra show two proton signals at 4.9 and $4.8 \mathrm{ppm}$ for CHO-P(MPEGAco-1,2DA) and 4.8 and $4.7 \mathrm{ppm}$ for CHO-P(MPEGAco-1,3DA) corresponding to the formaldehyde protons forming the acetals correlating to the carbon resonance at around $90 \mathrm{ppm}$. The separation of the proton signal corresponds to the difference in the chemical environment exo- and endoto the oxygens in the ring (Figure 4). The ${ }^{1} \mathrm{H}$ NMR analysis for CHO-P(MPEGA-co$1,2 \mathrm{DA})$ starting from $40 \% 1,2-\mathrm{DA}$ and $20 \% 1,2$-DA before functionalization resulted in a $25 \%$ and $20 \%$ post-functionalization efficiency. With this we obtain two polymers yielding $9.81 \mathrm{wt} \%$ and $3.92 \mathrm{wt} \%$ formaldehyde for the 5-memberd ring acetal formaldehyde prodrug polymers. We observed a lower post-functionalization efficiency forming the 6-membered ring acetal formaldehyde prodrug of $16 \%$ and $7 \%$ for $40 \%$ 1,3-DA and 20\% 1,3-DA respectively. CHO-P(MPEGA-co-1,3DA) with 6.45 and $1.50 \mathrm{wt} \%$ for $40 \% 1,3 \mathrm{DA}$ and $20 \% 1,3 \mathrm{DA}$ respectively as was obtained (Table 1 ). 


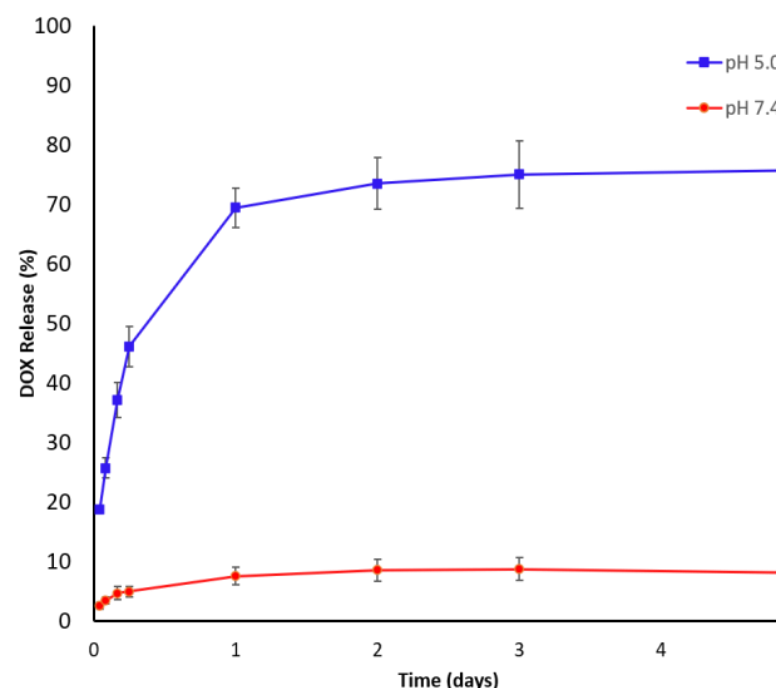

Fig. 7. Release of DOX from partially reduced $8 \%$ OPD, $2.7 \mathrm{mM}$ ketoxime/alkoxyamine nanoparticles in sodium acetate-acetic acid buffer ( $\mathrm{pH}$ 5.0) (blue line) and PBS ( $\mathrm{pH} 7.4)$ (red line) containing $0.1 \% \mathrm{v} / \mathrm{v}$ Tween- 80 at $37^{\circ} \mathrm{C}$ over 5 days reported as an average of measurements in triplicate.
In order to evaluate the formaldehyde release and $\mathrm{pH}$ responsiveness in aqueous environments, the prodrugs were suspended in either sodium acetate-acetic acid buffer ( $\mathrm{pH} 5.0$ ) or phosphate-buffered saline (PBS) (pH 7.4) inside $0.1-0.5 \mathrm{~K}$ MWCO dialysis Floata-Lyzers ${ }^{\circledR}$. The Floata-Lyzers ${ }^{\circledR}$ were placed inside centrifugal tubes

containing the corresponding release media at $37{ }^{\circ} \mathrm{C}$ from which aliquots were collected at specific times. The collected samples were analyzed via Purpald ${ }^{\circledR}$ colorimetric analysis. The Purpald $®$ assay was chosen in this case over other techniques such as chromotropic acid or acetylacetone methods because of the superior sensitivity and being able to conduct the assay at room temperature which allowed the use of 96-well plates. According to our results, the cumulative release of formaldehyde in acidic $\mathrm{pH}$ is considerably faster than from physiological $\mathrm{pH}$, where in the first 24 hours almost $80 \%$ formaldehyde is released compared to about $10 \%$ in neutral $\mathrm{pH}$ (Figure 5). After the first 24 hours the released is kept constant for the duration of the experiment to around $80 \%$ in $\mathrm{pH} 5$ and $10 \%$ in $\mathrm{pH} 7.4$. This result indicates that drug release is not favorable under physiological $\mathrm{pH}$ but instead faster in acidic conditions which is promising for applications in cancer therapies. ${ }^{19-21}$ In addition, it is worth mentioning that there is not a very significant difference in the formaldehyde release between the 5-membered and the 6-membered acetal. Although the release from the CHO-P(MPEGA-co-1,2DA) is slightly faster achieving $82 \%$ in 72 hours compared to $77 \%$ in 72 hours for CHO$\mathrm{P}(\mathrm{MPEGA}-\mathrm{co}-1,3 \mathrm{DA})$. This small difference could be attributed to the ring 
thermodynamic stability of the 6-membered ring in CHO-P(MPEGA-co-1,3DA) in comparison to the 5-membered ring in CHO-P(MPEGA-co-1,2DA).

The nanoparticles were made by intermolecular crosslinking reaction of poly $(\delta$ valerolactone-co-2-oxepane-1,5-dione) (P(VL-co-OPD)) with bis(aminooxy)PEG-3 via oxime click chemistry [27] (Figure 6). For this project, the low concentration (2.7 $\mathrm{Mm})$ and an OPD percentage (8\%) in the polymer backbone were chosen with the goal to form nanoparticles below $200 \mathrm{~nm}$. Having nanoparticles of less than $200 \mathrm{~nm}$ has shown to be beneficial for biomedical applications due to the vascular enhance permeability and retention (EPR) effect that is associated with tumors retaining particles.[34] The particles formed through this crosslink reaction contains oxime bonds which are cleavable at $\mathrm{pH} 5.0$ but can also be reduced to form stable alkoxyamine bonds. For this work, we chose to form particles with 50\% ketoxime bonds and $50 \%$ alkoxyamine bonds, because we anticipate the partial reduction of the crosslink chemistry will provide a tailored drug release and degradation profile ideal for the delivery of the DOX. We were able to obtain particles with sizes of $195 \pm 65 \mathrm{~nm}$ according to dynamic light scattering (DLS) and $141 \pm 28 \mathrm{~nm}$ as measured from transmission electron microscopy (TEM).

Doxorubicin was encapsulated in the nanoparticles through a developed nanosolubilization technique in which, DOX and the nanoparticles were solubilized in minimal amount of DMSO and coated with water containing $1 \mathrm{wt} \% \mathrm{D}-\alpha$-tocopherol polyethylene glycol 1000 succinate. The mixture was centrifuged in two cycles in order to collect the DOX-loaded particle pellet and finally washed with excess water and lyophilized to remove any water remaining from the resulted DOX-loaded particles. The drug loading was determined via high performance liquid chromatography (HPLC) to be $14 \mathrm{wt} \%$ DOX with an average encapsulation efficiency of $68 \%$.

The resulting DOX-loaded particles were then used to evaluate the drug release profile and $\mathrm{pH}$ responsiveness at $\mathrm{pH} 5.0$ and $\mathrm{pH}$ 7.4. The particles were suspended in either sodium acetate-acetic acid buffer ( $\mathrm{pH}$ 5.0) or phosphate-buffered saline (PBS) (pH 7.4) both containing $0.1 \% \mathrm{v} / \mathrm{v}$ Tween- 80 as a surfactant. Tween- 80 is commonly used for drugs with poor solubility when in vitro release assays are being conducted, since it promotes suspension of the drug in the release media hence a more accurate release profile can be obtained when aligned with true physiological conditions. ${ }^{35-37}$ 
The release profile (Figure 7) was obtained by diluting the DOX-loaded particles in the same aqueous media as mentioned before ( $\mathrm{pH} 5.0$ and 7.4). A faster release is exhibited at acidic $\mathrm{pH} 5.0$ in which almost $75 \%$ cumulative DOX release is obtained in the first 72 hours and maintained for the total duration of the experiment. Whereas a slower release is achieved under physiological $\mathrm{pH}$ with a maximum cumulative release of around $8 \%$ DOX in the first 24 hours and is constant throughout the remaining duration of the experiment. The $\mathrm{pH}$ responsiveness of the drug release experiment complements the result of the formaldehyde release from prodrugs and are promising for the synergistic release of DOX and formaldehyde in cancer therapies.

Finally, to analyze the dual effect of DOX-loaded particles and formaldehyde prodrugs, cell cytotoxicity experiments were conducted in mammalian breast cancer cells (4 T1). Previous work with DoxF and DoxSF has shown that only one equivalent of formaldehyde is necessary to form the DOX precursor that results in the DOX-DNA adduct. ${ }^{15}$ Therefore, we chose a 1:1 ratio of DOX-NP to formaldehyde prodrugs to study the cytotoxicity of our drug combination. In order to confirm that the active DOXformaldehyde prodrug is formed with only one equivalent and additional formaldehyde does not significant affect the overall treatment response, a cytotoxicity study of our dual delivery system was conducted at varying DOX:F ratios of 1:1, 1:2 and 1:50. Results indicated a minimal decrease in percent viability as more formaldehyde(1:2) is used, and an increase up to 50 equivalents of formaldehyde did not show any significant effect (Figure 8A). We concluded that additional formaldehyde does not increase the efficacy of the drug combination.

The cell viability assay was conducted with $4 \mathrm{~T} 1$ cells which were incubated in 96well plates for 3 hours for cell attachment and then treated with different media containing free DOX, DOX + formaldehyde, DOX-NP + formaldehyde, DOX + CHOP(MPEGA-co-1,2DA) or CHO-P(MPEGA-co-1,3DA), DOX-NP + CHO-P(MPEGAco-1,2DA) or CHO-P(MPEGA-co-1,3DA) in concentrations of $0.01,0.11$, and 10 $\mu \mathrm{g} / \mathrm{mL}$ and incubated for 24 hours (Figure 8B). After 24 hours the media containing 

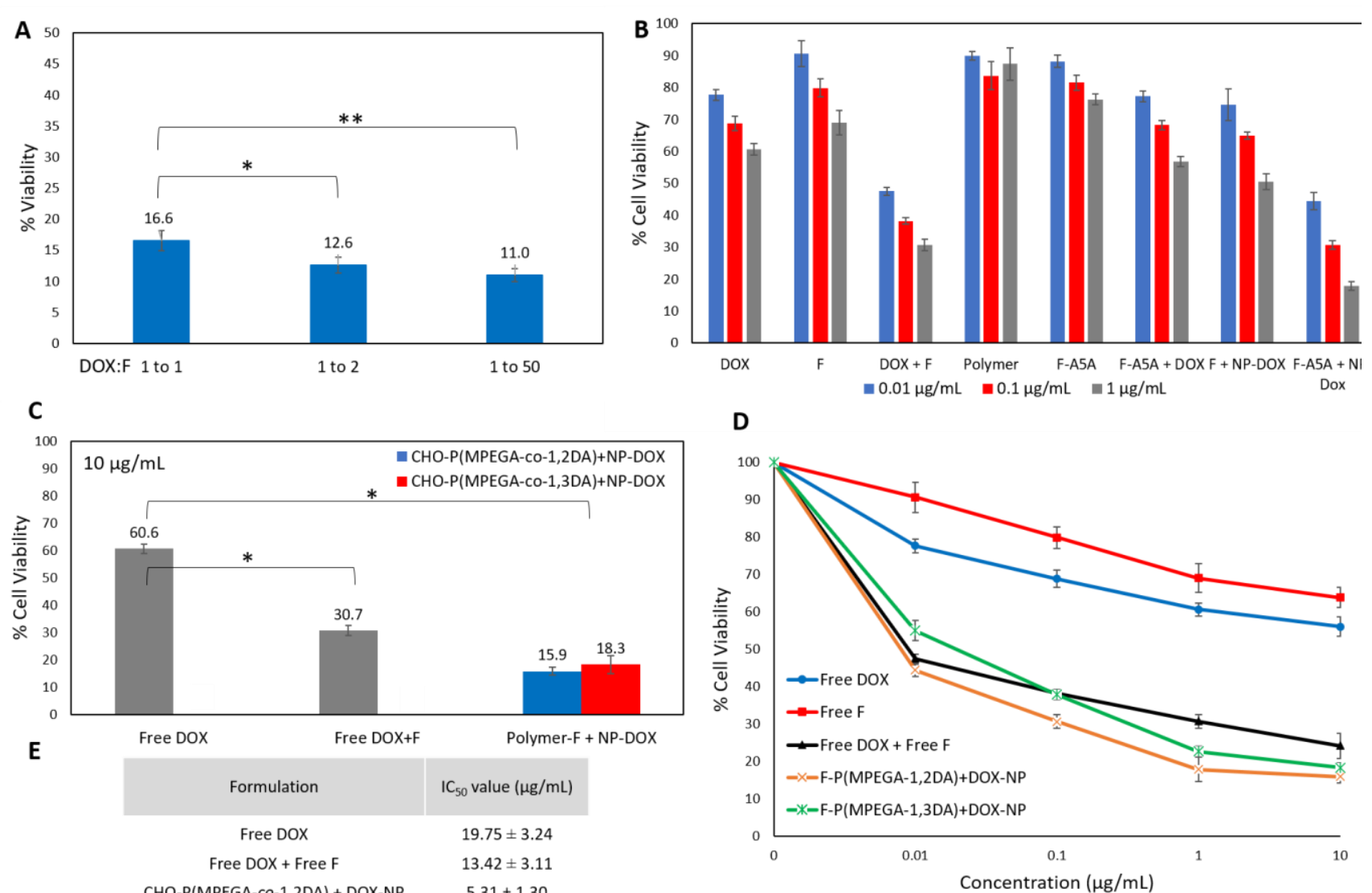

D

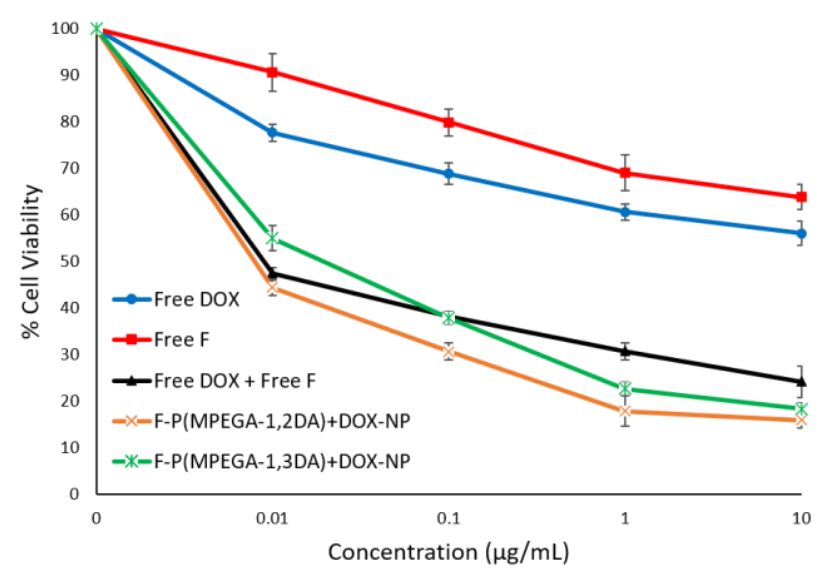

Fig. 8. (A) Cytotoxicity study at different DOX:Formaldehyde ratios of the dual delivery system (CHO-P(MPEGA-co-1,2DA) and DOX-NP) at a concentration of $10 \mu \mathrm{g} / \mathrm{mL}$ in $4 \mathrm{~T} 1$ cells after 24 hours. Asterisks indicate statistical significance; a single asterisk (*) at $p$-value $<0.05$ and a double asterisk $(* *)$ at $p$-value $<0.01$ determined via one-tailed $\mathrm{t}$ test performed using two-sample unequal variance. (B) Complete cell viability assay for CHO-P(MPEGAco-1,2DA) prodrug at concentrations of $0.01,0.1$ and $1 \mu \mathrm{g} / \mathrm{mL}$ after 24 hours in $4 \mathrm{~T} 1$ cells in combination with DOX-NP. (C) Cell viability to evaluate efficacy of resulting polymer matrix CHO-P(MPEGA-co-1,2DA) + DOX-loaded NP and combined CHO-P(MPEGA-co-1,3DA) + DOX-loaded NP compared to free DOX and free combined DOX $+\mathrm{F}$ at a concentration of $10 \mu \mathrm{g} / \mathrm{mL}$. Asterisks indicate statistical significance; a single asterisk $(*)$ at $p$-value $<0.05$ and a double asterisk $(* *)$ at $p$-value $<0.01$ determined via two-tailed t test performed using two-sample unequal variance. (D) $\mathrm{IC}_{50}$ values of free $\mathrm{DOX}$, combination of free DOX and free F, and our drug delivery system upon treatment with 4 T1 cells. Data expressed as a mean \pm SD (n=4) (E) Cell cytotoxicity of free DOX, free formaldehyde (F), combined free DOX and F (1:1), combined CHO-P(MPEGA-co-1,2DA) and DOX-loaded NP and combined CHO-P(MPEGAco-1,3DA) and DOX-loaded NP after $24 \mathrm{hrs}$ at varying concentrations. Each data point represents an average of measurements in triplicates.

drug formulations was aspirated and replaced with $20 \mu \mathrm{L}$ of MTS reagent containing phenazine methosulfate (PMS) in $100 \mu \mathrm{L}$ complete media and incubated for about 1 hour then absorbance was measured at $490 \mathrm{~nm}$. Analysing the results, co-administration of free DOX and free formaldehyde showed a significant decrease in the cancer cell growth, with free DOX achieving about $60.6 \pm 1.7 \%$ cell cytotoxicity against $30.7 \pm$ $1.8 \%$ of the co-administration (Figure $8 \mathrm{C}$ ). Next, we studied a combination of the DOX- 
NP with free formaldehyde. The free formaldehyde administered to the cells was molecular biology grade $36.5-38 \%$ formaldehyde solution in water. Here we could observe that the sustained release of the DOX had an advantageous effect in further inhibiting cancer cell growth. The dual drug combination of DOX-NP and formaldehyde prodrug was administered concerted to allow the immediate formation of the DOX-Schiff's base which will rapidly enter the cancer cell to form the desired DOX-DNA adducts. The cell viability assay confirmed the synergy effect of both DOX and formaldehyde. Our drug combination showed a 4-fold increase in cancer cell cytotoxicity than compared to free DOX and free formaldehyde together (2-fold) (Figure $8 C$ ). $\mathrm{IC}_{50}$ values obtained via regression analysis also corroborate our results of around 4-fold increase in cell death for our dual delivery system (Figure 8E). When comparing both polymers evaluated in this study, CHO-P(MPEGA-co-1,2DA) presents a slightly higher cell killing ability of $15.9 \pm 1.40 \%$ against $18.3 \pm 3.24 \%$ of CHOP(MPEGA-co-1,3DA). We attribute this effect to the faster release of the 5-membered ring in contrasts to the 6-membered ring polymer and therefore CHO-P(MPEGA-co1,2DA) matches to a higher degree that of DOX-NP and hence we will increase the synergistic effect.

Interestingly, higher concentrations of the drug combinations showed an increase in cell death in contrast with equal concentrations of either the free drugs or the DOX-NP with free formaldehyde (Figure 8D). We contribute this effect to the sustained release of both the DOX and formaldehyde at similar releases rates which allows the continuous formation of the DOX-formaldehyde reactive intermediate over a period of 6 hours. This cannot be achieved with either the two free drugs or the DOX-NP and free formaldehyde (Figure S10). These are promising results because using the drug combination delivery system allows for controlled delivery and sustained release of both DOX and formaldehyde in a more efficient way and thereby reducing the cardiotoxicity of the DOX and at the same time increasing the efficiency of the prodrug by 4 -fold. It is worth noticing that even at a low concentration of $0.01 \mu \mathrm{g} / \mathrm{mL}$ of the polymer matrix it achieves a toxicity $44.4 \pm 2.7 \%$ cell cytotoxicity, compared to free DOX with cell cytotoxicity of $60.6 \pm 1.7 \%$ at much higher concentration of $1 \mu \mathrm{g} / \mathrm{mL}$. 


\section{Conclusions}

In conclusion, we have demonstrated the successful design of a $\mathrm{pH}$-responsive dual delivery system triggering the release of DOX and formaldehyde at $\mathrm{pH} 5.0$, mimicking the extracellular matrix of tumors. This was made possible by combining polyacrylateformaldehyde prodrugs with polyester nanoparticles with partially reduced ketoxime/alkoxyamine crosslinks that can encapsulate DOX. Matching release kinetics favored the formation of the DOX-formaldehyde active intermediate (DOX-DNA adduct) to result in the maximum cell death rate (4-fold) in comparison to coadministration of free DOX and free formaldehyde (2-fold). The pH-trigger will allow a concerted release of the therapeutics at the place of action. Supporting the sustained release mechanism was the observation of the higher effect of the prodrug combination in contrast to free drug combinations at higher concentrations of $10 \mu \mathrm{g} / \mathrm{mL}$. We can conclude that this is the first example of a polymeric $\mathrm{pH}$ triggered formaldehyde prodrug that has the potential to significantly reduce the limiting clinically impact due to severe cardiotoxicity and at the same time improving the therapeutic index of DOX using pharmacological insights of the interplay of formaldehyde and DOX.

\section{Acknowledgements}

The authors thank the Robert A. Welch Foundation for the generous support of this research (\#H-E-0041) through the UH Center of Excellence in Polymer Chemistry. The authors also thank the National Science Foundation (CHE-1808664) for support. The authors also thank the Dr. Randall Lee laboratory for assistance and access to the Malvern Zetasizer Nanosystem analysis (Defense University Research Instrumentation Program grant (FA9550-15-1-0374) issued by the Air Force Office of Scientific Research). We also would like to thank Dr. Chengzhi Cai laboratory for giving us access to the Perkin Elmer Bio-Assay plate reader. 


\section{References}

[1] Lehár, J.; Krueger, A. S.; Avery, W.; Heilbut, A. M.; Johansen, L. M.; Price, E. R.; Rickles, R. J.; Short Iii, G. F.; Staunton, J. E.; Jin, X.; Lee, M. S.; Zimmermann, G. R.; Borisy, A. A., Nat. Biotechnol., 2009, 27, 659-666.

[2] Foucquier, J.; Guedj, M., Pharmacol. Res. Perspect., 2015, 3, e00149.

[3] Tacar, O.; Sriamornsak, P.; Dass, C. R., J. Pharm. Pharmacol., 2013, 65, 157 170 .

[4] Olson, R. D.; Mushlin, P. S., FASEB J., 1990, 4, 3076-3086.

[5] Arola, O. J.; Saraste, A.; Pulkki, K.; Kallajoki, M.; Parvinen, M.; VoipioPulkki, L.-M., Cancer Res., 2000, 60, 1789-1792.

[6] Smith, L.; Watson, M. B.; Kane, S. L.; Drew, P. J.; Lind, M. J.; Cawkwell, L., Mol. Cancer Ther., 2006, 5, 2115-2120.

[7] Mohamed, H. E.; El-Swefy, S. E.; Hagar, H. H., Pharmacol. Res. Commun., 2000, 42, 115-121.

[8] Minotti, G.; Ronchi, R.; Salvatorelli, E.; Menna, P.; Cairo, G., Cancer Res., 2001, 61, 8422-8428.

[9] Steinherz, L.; Steinherz, P., Pediatrician, 1991, 18, 49-52.

[10] Rephaeli, A.; Waks-Yona, S.; Nudelman, A.; Tarasenko, I.; Tarasenko, N.; Phillips, D.; Cutts, S.; Kessler-Icekson, G., Br. J. Cancer, 2007, 96, 16671674.

[11]Cutts, S. M.; Swift, L. P.; Pillay, V.; Forrest, R. A.; Nudelman, A.; Rephaeli, A.; Phillips, D. R., Mol. Cancer Ther., 2007, 6, 1450-1459.

[12] Engel, D.; Nudelman, A.; Levovich, I.; Gruss-Fischer, T.; Entin-Meer, M.; Phillips, D. R.; Cutts, S. M.; Rephaeli, A., J. Cancer. Res. Clin., 2006, 132, 673-683.

[13] Rephaeli, A.; Entin-Meer, M.; Angel, D.; Tarasenko, N.; Gruss-Fischer, T.; Bruachman, I.; Phillips, D. R.; Cutts, S. M.; Haas-Kogan, D.; Nudelman, A., Invest. New Drugs, 2006, 24, 383-392.

[14] Cutts, S. M.; Rephaeli, A.; Nudelman, A.; Hmelnitsky, I.; Phillips, D. R., Cancer Res., 2001, 61, 8194-8202. 
[15] Post, G. C.; Barthel, B. L.; Burkhart, D. J.; Hagadorn, J. R.; Koch, T. H., J. Med. Chem., 2005, 48, 7648-7657.

[16] Fenick, D. J.; Taatjes, D. J.; Koch, T. H., J. Med. Chem., 1997, 40, 2452-2461.

[17] Cutts, S. M.; Nudelman, A.; Rephaeli, A.; Phillips, D. R., IUBMB Life, 2005,

540

545

550 57, 73-81.

[18] Barthel, B. L.; Mooz, E. L.; Wiener, L. E.; Koch, G. G.; Koch, T. H., J. Med. Chem., 2016, 59, 2205-2221.

[19] Ojugo, A. S. E.; McSheehy, P. M. J.; McIntyre, D. J. O.; McCoy, C.; Stubbs, M.; Leach, M. O.; Judson, I. R.; Griffiths, J. R., NMR Biomed., 1999, 12, 495504.

[20]Fukamachi, T.; Chiba, Y.; Wang, X.; Saito, H.; Tagawa, M.; Kobayashi, H., Cancer Lett., 2010, 297, 182-189.

[21] Xiaomeng Zhang, Y. L. a. R. J. G., J. Nucl. Med., 2010, 51, 1167-1170.

[22] Nguyen, D.; Boyer, C., ACS Biomater. Sci. Eng., 2015, 1, 895-913.

[23]Li, W.-P.; Su, C.-H.; Tsao, L.-C.; Chang, C.-T.; Hsu, Y.-P.; Yeh, C.-S., ACS Nano, 2016, 10, 11027-11036.

[24]Duong, H. T.; Kamarudin, Z. M.; Erlich, R. B.; Li, Y.; Jones, M. W.; Kavallaris, M.; Boyer, C.; Davis, T. P., Chem. Comm., 2013, 49, 4190-4192.

[25] Mann, M. N.; Neufeld, B. H.; Hawker, M. J.; Pegalajar-Jurado, A.; Paricio, L. N.; Reynolds, M. M.; Fisher, E. R., Biointerphases, 2016, 11, 031005.

[26] Du, W.; Zhang, K.; Zhang, S.; Wang, R.; Nie, Y.; Tao, H.; Han, Z.; Liang, L.; Wang, D.; Liu, J.; Liu, N.; Han, Z.; Kong, D.; Zhao, Q.; Li, Z., Biomaterials, $2017,133,70-81$.

[27] Kendrick-Williams, L. L.; Harth, E., Macromolecules, 2018, 51, 1016010166.

[28] Niu, J.; Lunn, D. J.; Pusuluri, A.; Yoo, J. I.; O'Malley, M. A.; Mitragotri, S.; Soh, H. T.; Hawker, C. J., Nat. Chem. 2017, 9, 537-545.

[29] Nguyen, D.; Nguyen, T.-K.; Rice, S. A.; Boyer, C., Biomacromolecules, 2015, 16, 2776-2786.

[30] Xu, Y.; Hong, Y. J.; Tantillo, D. J.; Brown, M. K., Org. Lett., 2017, 19, $3703-$ 3706. 
[31] Rossi, N. A. A.; Zou, Y.; Scott, M. D.; Kizhakkedathu, J. N., Macromolecules, 2008, 41, 5272-5282.

[32] Ronco, L. I.; Basterretxea, A.; Mantione, D.; Aguirresarobe, R. H.; Minari, R. J.; Gugliotta, L. M.; Mecerreyes, D.; Sardon, H., Polymer, 2017, 122, 117 124.

[33]Ihre, H.; Hult, A.; Fréchet, J. M. J.; Gitsov, I., Macromolecules, 1998, 31, 4061-4068.

[34]Fang, J.; Nakamura, H.; Maeda, H., Adv. Drug Delivery Rev., 2011, 63, 136151.

[35] Abouelmagd, S. A.; Sun, B.; Chang, A. C.; Ku, Y. J.; Yeo, Y., Mol. Pharmaceutics, 2015, 12, 997-1003.

[36] Ketan T. Savjani, A. K. G., and Jignasa K. Savjani, ISRN Pharm., 2012, 1-10.

[37] Sivaram Nallamolu, V. R. J., Mallikarjun Chitneni and Prashant Kesharwani, ASPS, 2018, 2, 2-13. 